\title{
History of the Pierre Gy Sampling Gold Medal 2003-2015
}

Kim H. Esbensen

KHE Consulting, www.kheconsult.com

Adjunct professor Geological Survey of Denmark and Greenland (GEUS), Denmark

Adjunct professor Aalborg University, Denmark

highlight of every WCSB is the presentation of the Pierre Gy Sampling Gold Medal (PGSGM).

The first award committee was elected before WCSB1, and has subsequently been augmented by the successive award recipients. An original medal design, Figure 1, stems from Messieurs Pitard, Esbensen and Francois-Bongarcon and was taken over by the highly effective WCSB4 committee under the inspired leadership of chairman Sean Duggan, who was also instrumental in securing funding for the minting of five medals.

The Pierre Gy Sampling Gold Medal is awarded to individuals who have made "significant contributions to teaching and dissemination of the theory and practice of sampling". While the history of the PGSGM award presentations turned out to be convoluted and complex, it suffices to relate that the first recipient, selected with the help of Pierre Gy himself, was A.G. Royle (UK) as a sign of respect for his valuable help (teaching, translation) at a critical time in the career of Pierre Gy himself. Royle translated Gy's famous book: Sampling for Analytical Purposes (1998). Most unfortunately the awardee was unable to attend WCSB1 for its presentation due to serious illness in his family. It was therefore left to the WCSB1 chairman to make the presentation at a later, more appropriate, time. This first turned out to be possible in 2010, when "Le bon Royle" (Pierre Gy's own expression) was finally presented with his medal in his retirement home in the Cotswolds, UK, Figure 2.

After WCSB1, problems regarding the required sponsoring for the gold medal production ran into problems, which resulted in delays for the physical medal presentations at the time of the next conferences. A concerted effort finally solved the problems in time for WCSB4, when five medals could finally be minted and three could be presented simultaneously (a report of the presentation of the WCSB1 medal was also given at WCSB4). The official chronology of the PGSGM award could therefore now be

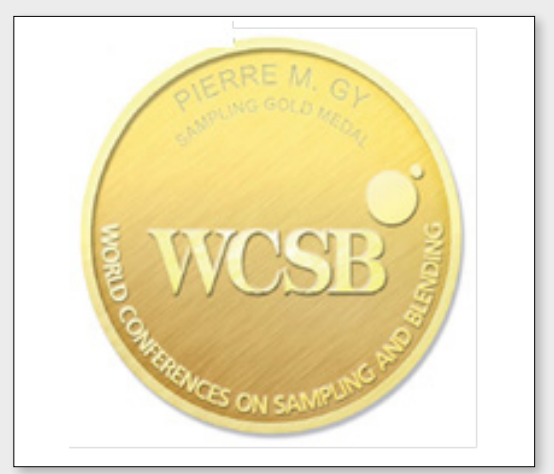

Figure 1. Pierre Gy Sampling Gold Medal (front side).

made up-to-date, and which hereafter goes into the official record in the following manner, see Figures 3 to 5.

A.G. Royle (1924-2013) (WCSB1, Esbjerg, 2003) [awarded 2010]

P.O. Minkkinen (WCSB2, Brisbane, 2005)

F.F. Pitard (WCSB4, Cape Town, 2009)

D. Francois-Bongarcon (WCSB4, Cape Town, 2009)
口. Carrasco (1950-2011) (WCSB5, Santiago de Chile, 2011) [awarded posthumously]

K.H. Esbensen (WCSB6, Lima, 2013)

R. Holmes (WCSB7, Bordeaux, 2015)

WCSB7, Bordeaux 2015 continued the by now well-established tradition and presented the seventh Pierre Gy Sampling Gold Medal to Ralph Holmes, Figure 7.

The recipient of the Gold Medal to be awarded at WCSB8, May 2017, Perth, has been selected. This will likely be the last awardee appointed in the current fashion. Since its inception, the award committee has gradually evolved by consisting of all accumulating Gold Medal recipients. Some of the members, present author included, are not overly happy with this somewhat irregular organisational arrangement. Plans are afoot to elect an independent committee at the WCSB8, Perth, in connection with establishment of a proper scientific association for our community. The Pierre Gy Gold Sampling medal will then become a committee organised by, and elected from the members of this new association.

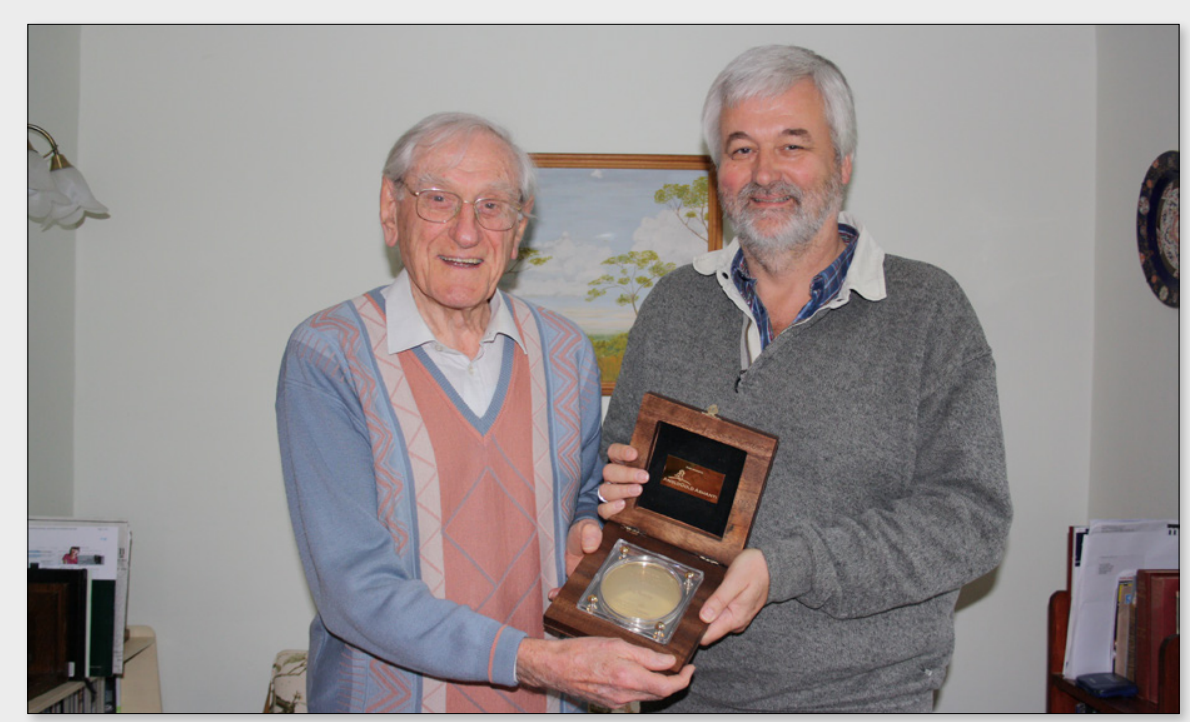

Figure 2. Presentation of WCSB1 Pierre Gy Sampling Gold Medal to A.G. Royle. The postponed presentation (2010) took place at Mr Royle's home in the Cotswolds, UK. 


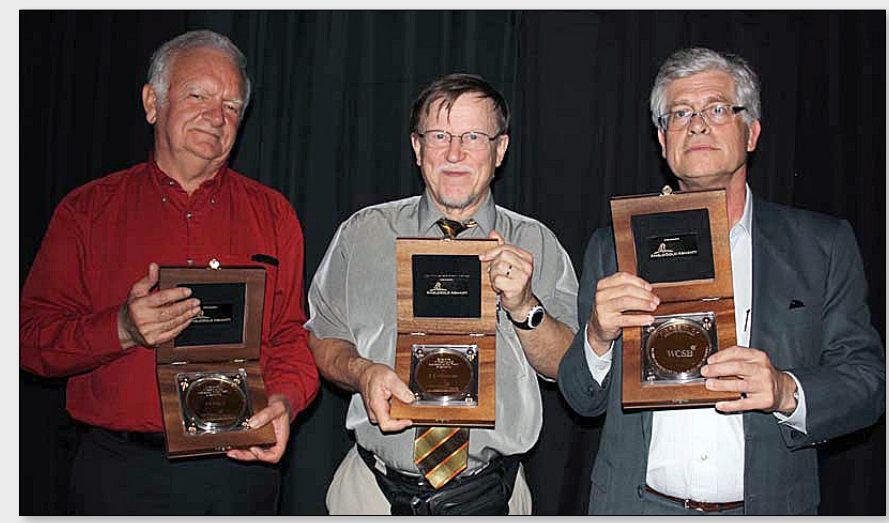

Figure 3. Pierre Gy Sampling Gold Medal awardees Francis Pitard (left), Pentti Minkkinen (centre) and Dominique Francois-Bongarcon (right). For logistical reasons presentation of the physical medals took place simultaneously at WCSB4, Cape Town, 2009.

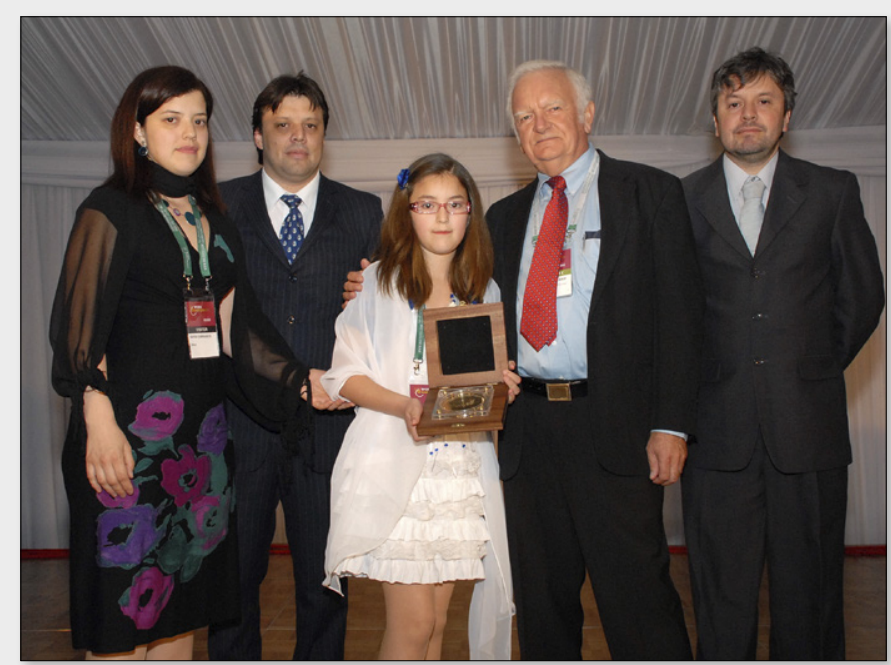

Figure 5. Presentation of the Pierre Gy Sampling Gold Medal to the family of Pedro Carrasco.

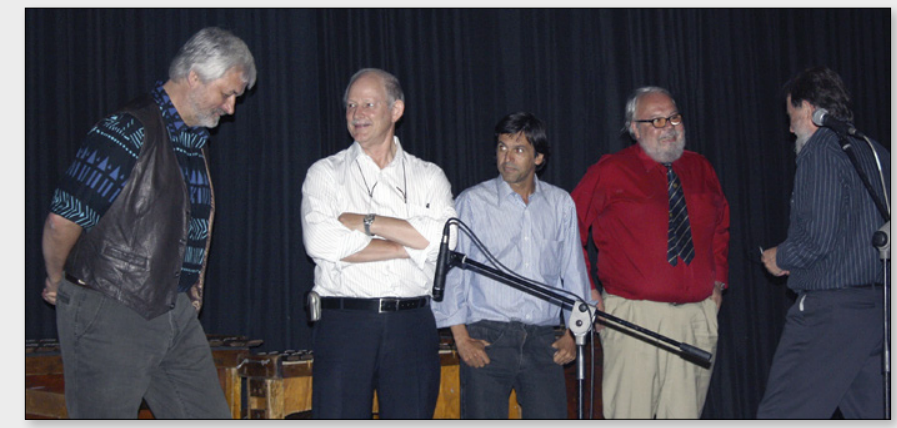

Figure 4. A line-up of WCSB chairmen (left to right): Kim H. Esbensen (WCSB1); Ralph Holmes (WCSB2); Joao Felipe de Costa (WCSB3). At right Sean Duggan (WCSB4), facing Pedro Carrasco, designated chairman WCSB5. The $5^{\text {th }}$ Pierre Gy Sampling Gold Medal was to be awarded to Pedro Carrasco, who tragically died only months before WCSB5. The Medal was presented posthumously to Pedro's children at the WCSB5 dinner by chairman Francis Pitard (Figure 5).

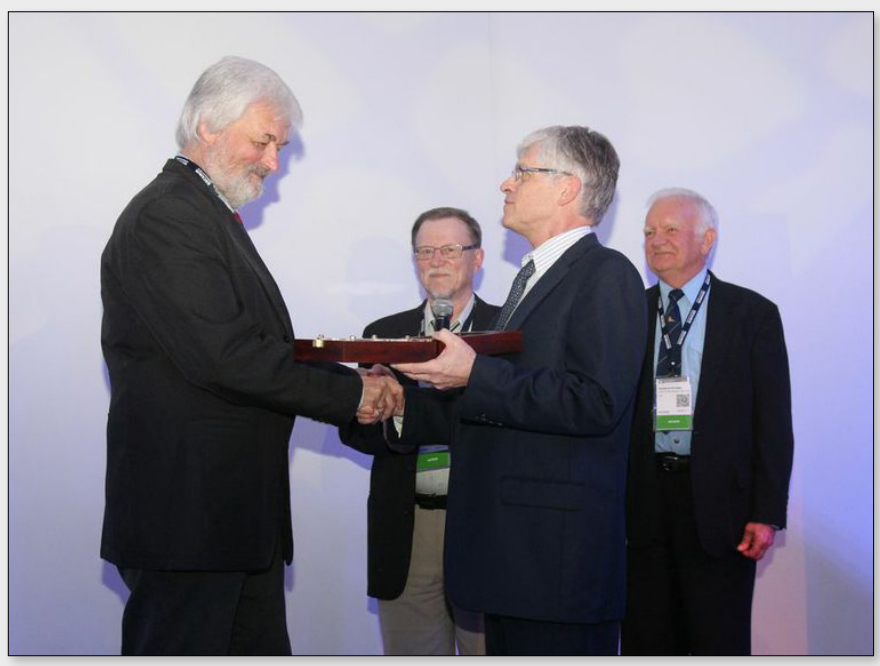

Figure 6. Presentation of the $6^{\text {th }}$ Pierre Gy Sampling Gold Medal to Kim H. Esbensen took place, now in regular fashion, at WCSB6, Lima, Peru, 2013

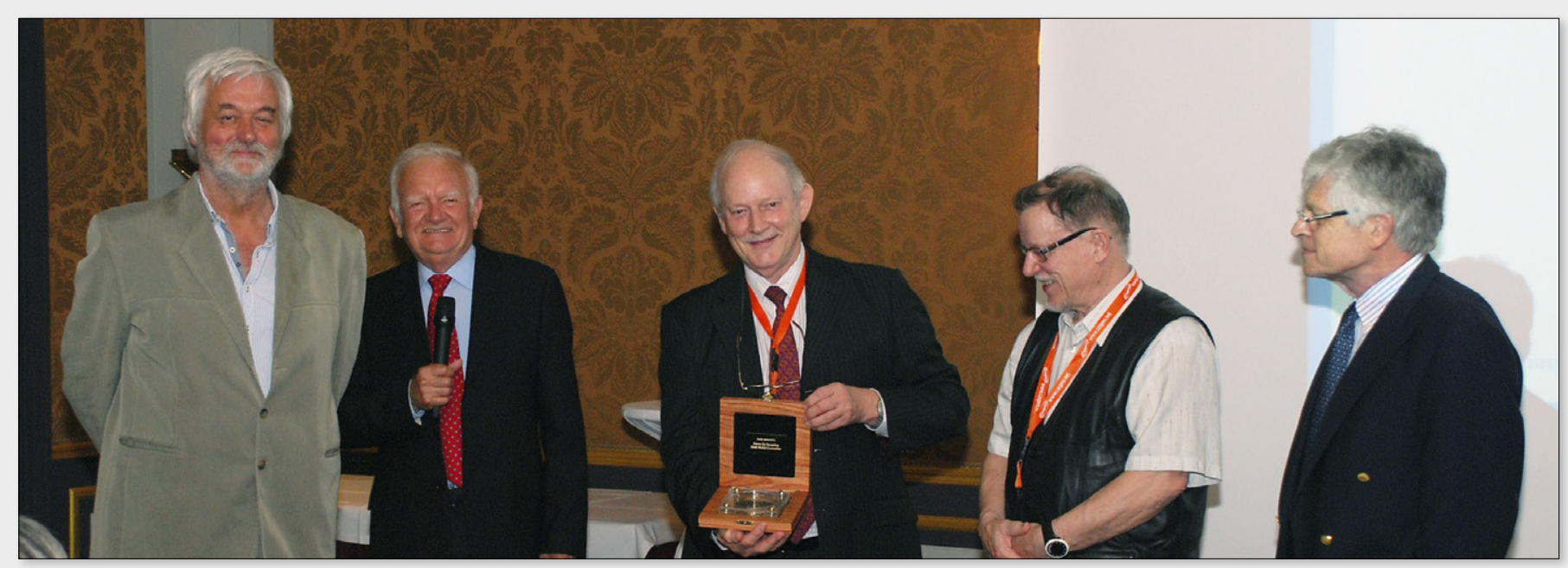

Figure 7. Ralph Holmes with the 7.th Pierre Gy Sampling Gold medal. 